undiscovered defects. It must be clearly understood that school health work is not curative medicine, but preventive medicine.

If this service is further curtailed it would be the most unfortunate policy this, or any, community could possibly adopt. It would set us back many years. The results in increased disabilities would persist into the coming generations. We see daily the children from other cities and towns where school health work is inadequate.

During the World War a large percentage of our youth were rejected because of uncorrected physical defects that should have been attended to in childhood. We should not permit a repetition of this terrible blunder. The birthright of our children must not be destroyed. As a measure of ultimate economy, proper child care must be given now even though other important activities must be sacrificed. Have we less foresight and less humanity than the ancient Greeks and Romans; who during their days of glory and physical perfection, in times good and bad, gave first place to the health supervision of their children whom they considered more precious than gold or anything else in the structure of the state? In times of depression we must not relax our vigilance for the health of the oncoming generations, for then we wili be a long time paying for our folly, and we will also be responsible for untold suffering of our future citizens.

\title{
HEALTH EXAMINATIONS IN SCHOOLS
}

EARL E. KleinschmidT, M. D.

School Physician, Ann Arbor, Michigan.

Instructor in Hygiene and Public Health, University of Michigan.

The periodic health examination has been placed in the curriculum of the public school as a response to the broadening scope of education and the widespread need for health conservation. It has been perhaps the most important factor influencing educators in the need for more extensive health guidance and instruction. In the idea the efforts of public health and public education have been united in a joint effort at health supervision and education. It has taken a long time to realize that the "whole child" goes to school both body and mind, and that education of the mind alone is one-sided and may be harmful. For this reason, the health examination has come to be recognized as having a definite place in the school curriculum.

Present day concepts as to the purpose of the health examination in the school may in general be summed up as follows:

1. To educate the child in habits of right living.

2. To appraise the physical, mental and emotional health status of the child and to adjust the school day to the child's especial needs and development.

3. To establish a health consciousness in the child.

4. To establish an interest in personal health and hygiene. 
5. To eradicate physical, mental and emotional defects found in school children through early discovery and correction where possible.

6. To stimulate an interest in the acquisition of correct health knowledge.

7. To cooperate with the parent in guiding the growth and development of the child.

8. To establish right attitudes and ideals toward healthy living.

In performing the health examination the physician investigates the health status of the child very carefully and if facilities permit, makes whatever laboratory examinations that appear necessary. $\mathrm{He}$ neglects no system or organ in need of attention. This enables him to detect significant deviations from the normal at an early age, long before the condition may have become at all serious. He is consequently better able to guide the child and advise the parent. In so doing he has impressed the child and parent with the reasonableness of periodic examinations. He no longer remains an emergency man. Instead, he becomes a guide and counsellor, a maintenance man as it were. He should exemplify a true guardian and teacher of health.

The child sees the physician as being more interested in keeping him healthy than in attending to his troubles in time of sickness. He finds the physician interested in his diet, personal hygiene, living habits, and his very routine of life. This is all very interesting to the child, and, because of its personal nature it inveigles him the more. The situation is an excellent one for providing the child with an educational experience of lasting value. However, to accomplish this both the teacher and pupil must be enlightened as to the purpose, meaning, content, methods, and value of this experience prior to the actual examination.

The educational value coming from the health examination depends on adequate preparation and definition in the language of both teacher and pupil. Habit formation and understanding can only result when an intelligent meaning relationship is attached to the experience. It must also be properly integrated with other educational functions of the school. This becomes necessary if the child is to receive the maximum encouragement in healthful living. It can be given most profitably as a part of a unit experience in health education. This the classroom teacher can very well arrange for. First, however, the problem must be sufficiently clear to her. Literature and the aid of a health supervisor will enable her to do this. Stimulating discussion and activity should be planned which leads the children to inquire as to, "What is a Health Examination?", "Why have a Health Examination?", "How can the doctor tell we are healthy?", etc. With this sort of an approach there results a wholesome curiosity and a better understanding of the work of the doctor and nurse. Next, in aiding children in solving the problem presented 
them, actual opportunities should be given them by having a health examination. This may be carried out at the time that each class reaches this portion of the health project.

The child enters the experience in an active capacity eager to ask the physician questions. Understanding replaces fear and the child naturally develops a friendly attitude toward the physician. Health takes on a direct, personal relationship quite as important to the child as the acquisition of proper habits of study. He learns that it is quite as desirable to see a physician when well as when sick. Further, the idea of seeing a physician when well appeals to him far more than when he is stricken with illness. It is conceded that the health examination can be but part of the process of educating the child in health. The remainder must come from the home and the classroom. Health-minded parents and teachers are a necessity.

Probably the greatest good next to the influence on the child can come from parent participation. The examination has equally as much educational value for the parent as for the child. The parent is given the opportunity to both observe and become acquainted with the normal findings and the deviations from the normal. They are informed of both the nature and importance of defects found. Of necessity the physician must inquire into the health history of both the parent and the child. This aftords him an ideal opportunity for teaching health in its various aspects. It is, perhaps, the school physician's greatest opportunity in cementing relations between the school and home.

With the completion of the examination, the interest of the child is best directed toward an appraisal of the experience by the classroom teacher and parent. Such questions as, "When should we have another examination?", "How can we live so as to keep our bodies in health?", and "How healthy is our class?", are a few around which discussion can be developed in the classroom and home to fix the experience definitely in the minds of children. The value of the follow-up lies in the application of the physician's findings and suggestions. It may take the form of a personal letter to parents with a summary of findings and with suggestions for further interesting them in the health of their children. It should also include a brief statement explaining the necessity for early correction of defects,possibly a change in health habits, or the need for protection against disease. This, of course, may be omitted if the parent attends the examination.

Suggestions to teachers are most necessary in giving them an understanding of the physical, mental, and emotional status of the child. Both the teacher and the school nurse perform a difficult service in endeavoring to arrange the curriculum to fit the needs of the child and to effect any assistance that may become necessary. 